\title{
PENGARUH SOCIAL NETWORK MARKETING (SNM) DAN ELECTRONIC WORD OF MOUTH (EWOM) TERHADAP MINAT BELI PELANGGAN
}

\author{
Wenny Kartika Susanto \\ Program Studi Magister Manajemen Universitas Tarumanagara \\ wennykartika94@gmail.com \\ Keni \\ Program Studi Magister Manajemen Universitas Tarumanagara
}

\begin{abstract}
Competition that is getting more competitive in smartphone industry has made customers feel quite difficult in deciding which product the customers should buy. This is because companies are doing marketing through mass media, both offline and online. Companies are trying to change customers' way of thinking through emotion, need, want, and demand. Nowadays, in this globalization the traditional retailers are facing big challenge because young generation is starting to switch to online shopping. This fact poses as threat for traditional retailers, but can also be used as opportunity due to easy access to product and brand via social media. Therefore, this research objective was to find what the influences of social network marketing and electronic word of mouth (independent variables) toward customer purchase intention (dependent variable). Quantitative research was chosen as the method of this research. The population was smartphone users from $26-50$ years old in Jakarta. Non - sampling method, specifically convenience sampling was used because this method allowed researched to approach random respondent easily. The researcher used 166 questionnaires as sample size. 166 valid data were analysed with Structural Equation Modelling to test hypothesises in the research. There are two hypothesises tested on this research. Based on analysis, all hypothesises are supported. In conclusion, the most significant value is Social Network Marketing (SNM) which contributed $35.3 \%$ toward purchase intention. Based on findings, it is suggested for the company to pay more attention in marketing activities at social media by giving positive experience to customers so that the customers can give positive feedback in social media as reference for future customers.
\end{abstract}

Abstrak: Persaingan yang semakin ketat di industri smartphone membuat pelanggan cukup sulit dalam menentukan produk apa yang sebaiknya pelanggan beli. Hal ini dikarenakan para perusahaan melakukan pemasaran melalui media masa baik secara offline maupun online. perusahaan berusaha untuk mengubah cara berpikir pelanggan melalui emosi, kebutuhan, keinginan, dan permintaan. Pada saat ini, di era globalisasi sekarang para pedagang eceran tradisional menghadapi tantangan yang besar dikarenakan generasi muda mulai beralih ke online shopping. Fakta ini menjadi ancaman bagi pedagang eceran tradisional, tetapi juga dapat digunakan sebagai kesempatan dikarenakan kemudahan akses terhadap produk dan merek melalui media sosial. Oleh karena itu, tujuan penelitian ini adalah untuk mengentahui pengaruh social network marketing dan electronic word of mouth (variabel bebas) terhadap minat beli pelanggan (variabel tidak bebas). Penelitian kuantitatif dipilih sebagai metode penelitian. Populasi adalah pengguna smartphone dari usia 26 - 50 tahun di Jakarta. Metode non - sampling, lebih tepatnya convenience sampling digunakan karena metode ini membiarkan peneliti untuk mendekati responden secara acak dengan mudah. Peneliti menggunakan 166 kuesioner sebagai ukuran sampel. 166 data valid dianalisa menggunakan Structural Equation Modelling untuk menguji hipotesis dalam penelitian. Terdapat dua hipotesis dalam penelitian ini. Berdasarkan analisis, semua hipotesis didukung. Kesimpulannya, nilai yang paling signifikan adalah Social Network Marketing (SNM) yang berkontribusi $35,3 \%$ terhadap minat beli. Berdasarkan penemuan, disarankan kepada 
perusahaan memberi perhatian lebih dalam kegiatan pemasaran di media sosial dengan cara memberikan pengalaman positif kepada pelanggan sehingga pelanggan dapat memberikan umpan balik positif dalam media sosial sebagai referensi bagi calon pelanggan.

Keywords: Social Network Marketing, Electronic Word of Mouth, Purchase Intention

\section{PENDAHULUAN}

Teknologi selalu berkembang dan merupakan salah satu aspek yang tidak bisa dipisahkan dalam kehidupan manusia di era globalisasi saat ini. Telepon genggam sebagai gadget yang multifungsi terus dikembangkan hingga akhirnya tercipta istilah ponsel pintar (smartphone). Persaingan yang semakin ketat di industri ini membuat pelanggan cukup sulit dalam menentukan produk apa yang sebaiknya pelanggan beli. Hal ini dikarenakan para perusahaan melakukan pemasaran melalui media masa baik secara offline maupun online. Perusahaan berusaha untuk mengubah cara berpikir pelanggan melalui emosi, kebutuhan, keinginan, dan permintaan. Menurut Krbova dan Pavelek (2015), di era globalisasi sekarang para pedagang eceran tradisional menghadapi tantangan yang besar dikarenakan generasi muda mulai beralih ke online shopping. Perubahan pada pola hidup ini menunjukkan bahwa para pelaku bisnis tradisional harus mampu menyesuaikan diri terhadap perubahan ini dan mengakomodasi sesuai perubahan.

Dunia saat ini dikelilingi oleh teknologi canggih dimana pemasaran yang dilakukan perusahaan pun mulai beralih dari offline ke online. Maraknya media sosial telah mengubah cara berkomunikasi dan berpengaruh terhadap strategi komunikasi pemasaran yang dilakukan oleh perusahaan. Evolusi ini telah melahirkan potensi dan kesempatan baru terhadap bisnis dan perdagangan dikarenakan akses terhadap produk dan merek perusahaan mampu menjangkau pelanggan secara luas dalam waktu singkat. Berdasarkan data dari Hootsuite (dalam Zaenal, 2017), perkembangan pengguna media sosial di Indonesia dimana sampai pada Januari 2017 mencapai 106 juta pengguna aktif. Saat ini mulai banyak penelitian yang meneliti mengenai pemasaran online, namun masih banyak terdapat kekosongan yang patut diteliti. Seperti halnya dalam penelitian yang dilakukan oleh Toor, et al. (2017) mengenai pengaruh media sosial terhadap minat beli pelanggan dengan keterlibatan pelanggan sebagai variabel mediasi. Sehubungan dengan keterbatasan ruang lingkup pada penelitian Toor, et al. (2017), dalam penelitian ini peneliti akan menambahkan variabel electronic word of mouth $(e W O M)$ untuk mengisi kekosongan penelitian sebelumnya namun dengan subjek penelitian yang berbeda.

Berdasarkan latar belakang di atas, maka tujuan dari penelitian ini adalah untuk mengidentifikasi pengaruh social network marketing (SNM) dan electronic word of mouth $(e W O M)$ terhadap minat beli pelanggan.

\section{TINJAUAN PUSTAKA}

\section{Social Network Marketing (SNM)}

Barhemmati dan Ahmad (2015: 307) menjelaskan "social network refers to sites allowing users to create profiles on the site, to post information and share that information and communicate with other users of the site." Menurut Assaad dan Gomez (2011:19), "the core of any business is the customers, and social networking represents an opportunity to build even closer and more profitable relationships with customer." Berdasarkan definisi dari para ahli tersebut, maka social network marketing (SNM) dapat diartikan sebagai pemasaran yang dilakukan oleh perusahaan melalui media sosial secara online. 


\section{Electronic Word of Mouth (eWOM)}

Cong dan Zheng (2017: 544) menyatakan electronic word of mouth (eWOM) sebagai cara "consumers transfer information of related personal experience, views, comments about the product, service or brand through the network channels to other consumers." Menurut Thurau, et al. (2004:39), electronic word of mouth (eWOM) merupakan "any positive or negative statement made by potential, actual, or former customers about a product or company, which is made available to a multitude of people and institutions via the Internet." Berdasarkan definisi dari para ahli tersebut, maka electronic word of mouth (eWOM) dapat diartikan sebagai pertukaran informasi mengenai produk atau jasa yang terjadi di dunia virtual dikarenakan keberadaan internet yang telah tersebar hampir di seluruh dunia.

\section{Minat Beli}

Cong dan Zheng (2017:544) menjelaskan minat beli pelanggan sebagai "willingness and decision expressed by consumers in the process of actual purchase." Minat beli dapat sewaktu-waktu berubah dengan adanya pengaruh dari faktor eksternal seperti informasi mengenai pengalaman pelanggan saat membeli produk, maupun dari faktor internal seperti kondisi keuangan. Minat beli dapat diartikan sebagai keinginan pelanggan untuk membeli suatu produk atau mencoba suatu jasa.

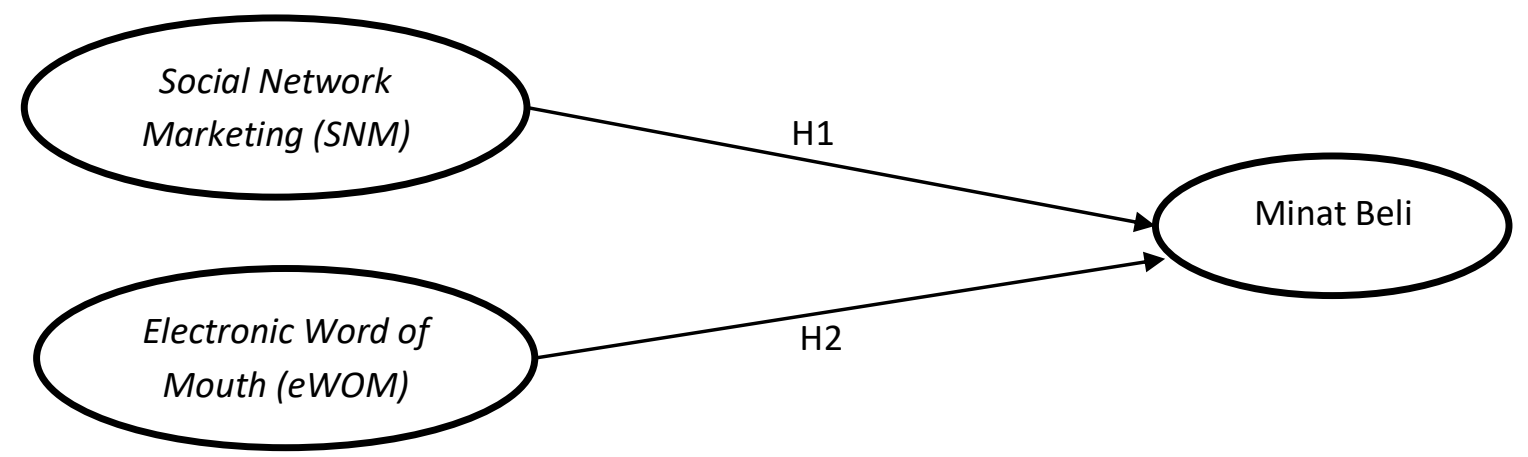

Gambar 1

Kerangka Konseptual

\section{Pengembangan Hipotesis}

\section{Kaitan antara social network marketing (SNM) dan minat beli}

Dalam penelitiannya, Toor, et al. (2017) mengungkapkan bahwa social network marketing (SNM) berpengaruh positif terhadap minat beli pelanggan. Social network marketing (SNM) menyediakan forum yang interaktif kepada pelanggan yang dapat ditujukan kepada siapa saja. Hal yang sama juga diungkapkan oleh Baird dan Parasnis (2011) bahwa social network marketing (SNM) dapat menawarkan pengiriman informasi yang tersebar luas dan dapat menarik perhatian pelanggan secara cepat dimana hal ini mampu meningkatkan minat beli pelanggan. Berdasarkan hasil penelitian terdahulu tersebut, peneliti merumuskan hipotesis pertama $\left(\mathrm{H}_{1}\right)$ dalam penelitian ini sebagai berikut:

$\mathrm{H}_{1}$ : Social network marketing $(S N M)$ berpengaruh positif terhadap minat beli pelanggan.

\section{Kaitan antara electronic word of mouth (eWOM) dan minat beli}

Sa'ait, et al (2016) menyatakan bahwa electronic word of mouth (eWOM) berpengaruh positif terhadap minat beli., dimana elemen akurasi eWOM mempunyai pengaruh paling kuat terhadap minat beli pelanggan. Hal ini berarti bahwa perusahaan harus mampu memastikan dan menjaga supaya ketepatan informasi yang disampaikan melalui 
electronic word of mouth (eWOM) haruslah tepat dan sesuai seperti yang diinginkan. Pelanggan lebih tertarik untuk berbagi dan mengkomunikasikan pengalaman berbelanja melalui internet dimana dalam dunia virtual ini hubungan antar pengguna internet semakin sering dilakukan yang akan mempengaruhi minat beli calon pelanggan yang menerima informasi yang dibagikan tersebut (Cong \& Zheng, 2017). Berdasarkan hasil penelitian terdahulu tersebut, peneliti merumuskan hipotesis kedua $\left(\mathrm{H}_{2}\right)$ dalam penelitian ini sebagai berikut:

$\mathrm{H}_{2}$ : Electronic word of mouth (eWOM) berpengaruh positif terhadap minat beli pelanggan.

\section{METODOLOGI PENELITIAN}

Penelitian kuantitatif dipilih sebagai metode penelitian. Populasi yang digunakan adalah para pengguna smartphone dengan rentang usia 26 - 50 tahun di Jakarta. Metode non - sampling, lebih tepatnya convenience sampling digunakan sebagai metode pengambilan sampel karena metode ini membiarkan peneliti untuk mendekati responden secara acak dengan mudah. Peneliti menggunakan 166 kuesioner sebagai ukuran sampel. Bagian pertama kuesioner terdiri dari profil responden yang digunakan sebagai subjek penelitian. Profil responden dalam penelitian ini berjumlah 166 yang terdiri dari 53\% laki-laki dan 47\% perempuan. Mayoritas responden $(31,33 \%)$ berusia 26 - 30 tahun. Mayoritas responden $(67,47 \%)$ berprofesi sebagai karyawan. Mayoritas responden $(45,78 \%)$ berpenghasilan $>\mathrm{Rp}$ 9.000.000 per bulan. Mayoritas responden (37,95\%) memilih Instagram sebagai akun media sosial yang paling sering digunakan. Bagian kedua terdiri dari hasil jawaban kuesioner berdasarkan skala Likert $1-7$ yang digunakan sebagai objek penelitian. Hasil jawaban kuesioner diolah dan diuji validitas dan reliabilitasnya menggunakan model pengukuran menggunakan software AMOS.

Dalam penelitian ini terdapat 2 variabel bebas (social network marketing (SNM) dan electronic word of mouth (eWOM)) dan 1 variabel tidak bebas (minat beli). Salah satu uji validitas yang dilakukan dalam penelitian ini adalah melalui uji average variance extracted (AVE). Menurut Kuncono (2013) dan Hair, et al. (2006), suatu indikator dikatakan valid apabila memiliki nilai $A V E>0,5$. Setelah melewati uji validitas, langkah selanjutnya adalah menguji reliabilitas indikator melalui uji construct reliability, dimana nilai construct reliability $(C R)>0,7$ (Hair, et al., 2006). Namun, nilai contruct reliability (CR) yang berada di antara 0,6 - 0,7 masih dapat diterima apabila validitas konstruk (indikator) dalam model adalah baik (Kuncono, 2013). Tabel 1 menunjukkan hasil uji validitas dan reliabilitas variabel dalam penelitian ini.

Tabel 1

Uji Average Variance Extracetd (AVE) dan Construct Reliability

\begin{tabular}{|l|c|c|c|c|}
\hline \multicolumn{1}{|c|}{ Variabel } & AVE & Keterangan & CR & Keterangan \\
\hline Social Network Marketing (SNM) & 0,7 & Valid & 0,909 & Reliabel \\
\hline $\begin{array}{l}\text { Electronic Word of Mouth } \\
(\text { eWOM })\end{array}$ & 0,8 & Valid & 0,934 & Reliabel \\
\hline Minat Beli & 0,5 & Valid & 0,615 & Reliabel \\
\hline
\end{tabular}

Sumber: Data primer yang diolah (2018)

\section{HASIL \& KESIMPULAN}

Setelah melewati uji validitas dan realitas, langkah selanjutnya adalah menguji kecocokan model struktural. Uji kecocokan model digunakan untuk menentukan apakah suatu variabel dapat diterima atau tidak. 
Tabel 2

Hasil Uji Kecocokan Model Struktural

\begin{tabular}{|l|c|c|c|}
\hline \multicolumn{1}{|c|}{$\begin{array}{c}\text { Pengukuran Tingkat } \\
\text { Kompatibilitas }\end{array}$} & $\begin{array}{c}\text { Tingkat yang } \\
\text { Dapat Diterima }\end{array}$ & Nilai & Keterangan \\
\hline Normed Chi Square $\left(x^{2} / d f\right)$ & $x^{2} / d f>5$ & 96,527 & Model sesuai data \\
\hline $\begin{array}{l}\text { Goodness of Fit Indices } \\
(\text { GFI) }\end{array}$ & $0,80 \leq \mathrm{GFI} \leq 0,90$ & 0,935 & $\begin{array}{c}\text { Kecocokan model } \\
\text { mendekati baik }\end{array}$ \\
\hline CMIN/DF & $\mathrm{CMIN/DF} \leq 2$ & 1,269 & Kecocokan model baik \\
\hline $\begin{array}{l}\text { Adjusted Goodness of Fit } \\
\text { Index }(\text { AGFI) }\end{array}$ & $\mathrm{AGFI} \geq 0.90$ & 0,902 & Kecocokan model baik \\
\hline $\begin{array}{l}\text { Root Mean Square Error of } \\
\text { Approximation }(\text { RMSEA) }\end{array}$ & $\mathrm{RMSEA} \leq 0.08$ & 0,047 & Kecocokan model baik \\
\hline $\begin{array}{l}\text { Comparative Fit Index } \\
\text { (CFI) }\end{array}$ & $0.0 \leq \mathrm{CFI} \leq 1.00$ & 0,985 & Kecocokan model baik \\
\hline Tucker Lewis Index $(T L I)$ & $\mathrm{TLI} \geq 0.9$ & 0,981 & Kecocokan model baik \\
\hline
\end{tabular}

Sumber: Data primer yang diolah (2018)

Tabel 2 menunjukkan bahwa data penelitian telah memenuhi syarat uji kecocokan model struktural. Dalam penelitian ini, kriteria yang digunakan untuk menentukan apakah suatu hipotesis didukung atau tidak didukung adalah dengan memperhatikan nilai probabilitas (p) dan critical ratio (CR) pada regression weight. Menurut Santoso (2011), suatu hipotesis dinyatakan didukung apabila memiliki nilai $\mathrm{CR}>1,96$ dan nilai $\mathrm{P}<0,05$.

Tabel 3

Hasil Uji Hipotesis

\begin{tabular}{|l|c|c|c|c|}
\hline \multicolumn{1}{|c|}{ Pernyataan Hipotesis } & Koefisien Jalur & CR & P & Keterangan \\
\hline $\begin{array}{l}\mathrm{H}_{1} \text { : Social network marketing }(\mathrm{SNM}) \\
\text { berpengaruh positif terhadap minat } \\
\text { beli pelanggan. }\end{array}$ & 0,353 & 5,476 & 0,000 & Didukung \\
\hline $\begin{array}{l}\mathrm{H}_{2}: \text { Electronic word of mouth }(\mathrm{eWOM}) \\
\text { berpengaruh positif terhadap minat } \\
\text { beli pelanggan. }\end{array}$ & 0,308 & 4,507 & 0,000 & Didukung \\
\hline
\end{tabular}

Sumber: Data primer yang diolah (2018)

Berdasarkan data pada Tabel 3, hipotesis pertama $\left(\mathrm{H}_{1}\right)$ yang merumuskan bahwa social network marketing (SNM) berpengaruh positif terhadap minat beli pelanggan diterima karena memiliki nilai $\mathrm{CR}>1,96$ dan $\mathrm{P}<0,05$. Tabel 3 juga menunjukkan bahwa social network marketing (SNM) memberikan kontribusi terbesar terhadap minat beli, yakni sebesar 35,3\%. Hal ini sejalan dengan teori Toor, et al. (2017), serta Baird dan Parasnis (2011) yang telah diuraiakn dalam tinjauan pustaka. Pemasaran yang dilakukan oleh perusahaan melalui media apapun, baik online ataupun offline bertujuan untuk menarik perhatian para calon pelanggan agar dapat menjadi pelanggan dengan cara membeli produk yang ditawarkan. Pemasaran yang dilakukan oleh perusahaan melalui social network marketing (SNM) sebaiknya menonjolkan fitur utama untuk menarik perhatian calon pelanggan agar dapat mencoba sendiri produk yang ditawarkan sehingga meningkatkan minat beli. Perkembangan internet semakin pesat sehingga kebanyakan pelanggan, terutama yang akrab dengan dunia internet memilih datang ke toko fisik hanya untuk mencoba produk dan merasakan pengalaman menggunakan produk yang dipasarkan. Setelah mencoba dan mendapatkan 
informasi melalui pelayan toko, hal yang sering dilakukan adalah memeriksa informasi dengan yang tertera di internet. Namun, hal ini dapat berlaku sebaliknya. Pelanggan terlebih dahulu mendapatkan informasi melalui internet, kemudian memutuskan untuk mengunjungi toko untuk mencoba produk.

Berdasarkan data pada Tabel 3, hipotesis kedua yang merumuskan bahwa electronic word of mouth (eWOM) berpengaruh positif terhadap minat beli pelanggan diterima karena memiliki nilai $\mathrm{CR}>1,96$ dan $\mathrm{P}<0,05$. Hal ini didukung dengan hasil penelitian yang dilakukan olehh Sa'ait, et al. (2016), serta Cong dan Zheng (2017) yang telah diuraikan dalam tinjauan pustaka. Ulasan positif dari para calon pelanggan ataupun pelanggan seringkali menjadi bahan pertimbangan bagi calon pelanggan lainnya sebelum memutuskan untuk membeli suatu produk atau tidak. Apabila ulasan yang didapat melalui electronic word of mouth $(e W O M)$ dari calon pelanggan ataupun pelanggan mengenai produk tertentu yang bersifat positif, maka akan meningkatkan minat beli calon pelanggan baru. Hal ini juga berlaku sebaliknya. Apabila ulasan yang didapat melalui electronic word of mouth (eWOM) bersifat negatif, maka calon pelanggan yang awalnya berniat untuk membeli produk akan berpikir ulang atau bahkan dapat membatalkan minat beli pada saat itu juga. Oleh karena itu, electronic word of mouth (eWOM) berpengaruh terhadap minat beli pelanggan. Electronic word of mouth $(e W O M)$ harus diperhatikan oleh perusahaan agar tidak menurunkan citra perusahaan.

\section{DAFTAR PUSTAKA}

Assaad, W., \& Gomez, J. M. (2011). Social Network in Marketing (Social Network Marketing) Opportunities and Risks. International Journal of Managing Public Sector Information and Communication Technologies (IJMPICT), 2(1).

Baird, C. H., \& Parasnis, G. (2011). From Social Media to Social Customer Relationship Management. Strategy \& Leadership, 39(5), 30 - 37.

Barhemmati, N., \& Ahmad, A. (2015). Effects of Social Network Marketing (SNM) on Consumer Purchase Behavior through Customer Engagement. Journal of Advanced Management Science, 3(4).

Cong, Y., \& Zheng, Y. Q. (2017). A Literature Review of the Influence of Electronic Wordof-Mouth on Consumer Purchase Intention. Open Journal of Business and Management, $5,543-549$.

Hair, et al. (2006). Multivariate Data Analysis (Ed. 6). New Jersey: Pearson Education.

Krbova, P., \& Pavelek, T. (2015). Generation Y: Online Shopping Behaviour of the Secondary School and University Students. Acta Universitatis Agriculturae et Silviculturae Mendelianae Brunensis, 63(2), 567 - 575.

Kuncono, O. S. (2013). BAB V Hasil Penelitian: Analisis Model Pengukuran \& Model Persamaan Struktural. Diakses pada 15 Desember 2017 dari http://www.spocjournal.com/disertasi/310-bab-v-hasil-penelitian-analisis-modelpengukuran-a-model-persamaan-struktural.html

Sa'ait, N., Kanyan, A., \& Nazrin, M. F. (2016). The Effect of E-WOM on Customer Purchase Intention. International Academic Research Journal of Social Science, 2(1), 73 - 80.

Thurau, T. H., Gwinner, K. P., Walsh, G., \& Gremler, D. D. (2004). Electronic Word of Mouth Via Consumer Opinion Platforms: What Motivates Consumer to Articulate Themselves on the Internet?. Journal of Interactive Marketing, 18(1).

Toor, A., Husnain, M., \& Hussain, T. (217). The Impact of Social Network Marketing on Consumer Purchase Intention in Pakistan: Consumer Engagement as a Mediator. Asian Journal of Business and Accounting, 10(1).

Zaenal, A. (2017). Komponen Media Sosial 2017. Diakses pada 17 Maret 2018 dari https://www.slideshare.net/alizaenal/komponen-media-sosial-2017 
